\title{
DEFINITIVE SCREENING DESIGN FOR THE OPTIMIZATION OF FLEXOGRAPHIC WATER-BASED CYAN DYE REMOVAL FROM AQUEOUS SOLUTION BY nZVI-INDUCED FENTON PROCESS
}

\author{
Vesna Kecić ${ }^{1}(\mathbb{D})$, Miljana Prica ${ }^{1}$ (D), Eurđa Kerkez ${ }^{2}$ (D), Ognjan Lužanin ${ }^{3}$ (D), \\ Milena Bečelić-Tomin ${ }^{2}$ (D), Dragana Tomašević Pilipović ${ }^{2}$ (D), Anita Leovac Maćerak ${ }^{2}$ (D) \\ ${ }^{1}$ University of Novi Sad, Faculty of Technical Sciences, \\ Department of Graphic Engineering and Design, Novi Sad, Serbia \\ ${ }^{2}$ University of Novi Sad, Faculty of Sciences, Department of Chemistry, \\ Biochemistry and Environmental Protection, Novi Sad, Serbia \\ ${ }^{3}$ University of Novi Sad, Faculty of Technical Sciences, \\ Department of Production Engineering, Novi Sad, Serbia
}

\begin{abstract}
The paper investigates the potential use of nano-zero valent iron (nZVI) particles as a cheap, natural and effective catalyst in Fenton-like process for the removal of water-based Cyan dye from synthetic aqueous solution and printing effluent. The production of $n Z \mathrm{VI}$ nanoparticles is based on the environmentally friendly method, so-called green synthesis, using the extract from natural product, oak leaves. Characterization of oak-nZVI by SEM, EDS and TEM revealed the surface and spatial structural characteristics, as well as the morphology of the synthesized nanomaterial. The experiments were carried out in a batch mode technique, investigating the influence of dye concentration (20-180 mgL $\mathrm{L}^{-1}$ ), nanoparticles dosage (0.75-60 $\left.\mathrm{mgL}^{-1}\right), \mathrm{H}_{2} \mathrm{O}_{2}$ concentration (1-11 mM) and $\mathrm{pH}$ value of the solution (2-10) on the decolorization efficiency. A new generation of experimental designs, the definitive screening design (DSD), was used to optimize the process conditions, considering the individual and interaction effects of the factors that influenced the percentage of dye degradation. The optimum degradation efficiency of Cyan dye in synthetic solution was $87.24 \%$, within the operational parameters: initial dye concentration of $20 \mathrm{mgL}^{-1}, n Z \mathrm{VI}$ dosage of $25.69 \mathrm{mgL}^{-1}, \mathrm{H}_{2} \mathrm{O}_{2}$ concertation of $6.88 \mathrm{mM}$ and $\mathrm{pH}$ value of 2 . Under the optimum conditions real printing effluent was treated, and decolorization efficiency of $70.85 \%$ was achieved. The obtained experimental results show that the Fenton process is effective for the degradation of printing dye, implying to the fact that future work should be explored with additional Fenton process catalyst and for other printing dyes.
\end{abstract}

Key words: definitive screening design, nano zero valent iron, Fenton process, optimization, dye removal

\section{INTRODUCTION}

The printing industry is one of the most complex manufacturing industrial chains, covering the entire production cycle from raw materials (dyes, solvents, developers, photochemical baths) to final products (cardboard boxes, food packaging, newspapers, catalogues). The main environmental issue arising from printing process primarily regards water pollution, where the type and concentration of hazardous and harmful substances depends on the primary and secondary raw materials used in the production process, chemical reactions, process parameters, intermediates and final products (Kecić et al, 2017; Wang et al, 2018). However, the highest environmental load arises from dyes, known as difficult-to-eliminate organic compounds. Dyes released from printing industry are categorized as major ecological hazards, due to their non-biodegradability and chemically, photolytically and biologically highly stable nature (Kecić et al, 2018). Even in low concentrations, dyes are highly visible, they contribute to the esthetic pollution, reduce the photosynthetic activity within the water body and affect the symbiotic process. In addition, dyes affect the aquatic life and food chain, causing chemical pollution. The hazardous, toxic and carcinogenic nature of dyes is also well known, where a various physiological disorders in aquatic organisms happen by the consumption of dyes via food chain (Khemila et al, 2018).

Solvent-based printing dyes primarily achieved a large market share, but the fact that they contain up to $60 \%$ of volatile organic compounds, which have a potentially negative impact on the working and living environment, have led to their substitution with water-based dyes. The colored dye effluent discharge from printing facilities ia a growing concern worldwide and their treatment is always a challenging. The previous period in the field of environmental science and technology is characterized by the application of various techniques in the field of textile wastewater treatment (Mijin, 2017). Hovewer, prinitng 
wastwater generated after prinitng process are usually discharged into water bodies without previous treatment, therefore polluting environment in a large scale. Thus, there is a great need for the disclosure of alternative, efficient and cost-effective treatment effective techniques that will remove dyes from large volumes of printing effluents.

Various biological and physio-chemical processes, effective but still quite expensive, are used in order to remove dyes from effluents: adsorption, membrane filtration, microbial degradation, coagulation and ion exchange (Punzi et al, 2015; Lin et al, 2016; Brito et al, 2018; Lin et al, 2017). Among the mentioned remediation process, advanced oxidation processes (AOPs) are proven as highly effective in the oxidation of organic pollutants, due to the generation of highly reactive species - hydroxil radicals (HO.) in the medium, which are capable to attac the majority of persistence organic compounds. In Fenton system $\mathrm{HO}$ - are generated through the catalytic reaction of $\mathrm{Fe}(\mathrm{II}) / \mathrm{Fe}(\mathrm{III})$ in the presence of hydrogen peroxide. So far, various iron sources have been applyed, categorizing the Fenton process as heterogeneous, homogeneous and Fenton-like process (Bilinska et al, 2016). Recently Fenton-like system have demonstrated high removal efficiency towards the application of nZVI particles as catalyst, mainly because of its nontoxic form, small particle size, large specific surface area, high density and high chemical reactivity in aqueous media. Based on these characteristics, the nZVI technology could become a promising approach for treating industrial dyes wastewater (Stefaniuk et al, 2016).

In this study application of nZVI-induces Fenton process was performed in order to acchive decolorization of water-based cyan dye synthehtic aqueous solution and real prinitng effluent. The influence of fundamental operative parameters, such as dye concentration, catalyst dosage, hydrogen peroxide concentration and $\mathrm{pH}$, as well as the process optimization were evaluated by using novel DSD method.

\section{MATERIALS AND METHODS}

\subsection{Reagents}

Hydrogen peroxide (30\%) was obtained from NRK engineering, Serbia, $\mathrm{NaOH}(>98.8 \%)$ was purchased from $\mathrm{POCH}$, while $\mathrm{ccH} 2 \mathrm{SO} 4$ (>96\%) was produced by J.T. Baker. All chemicals used in this study were of analytical grade and employed without further purification.

Cyan flexographic dye (Figure 1) was supplied from Flint group. This dye was used during water-based flexographic process in one printing facility in Novi Sad. Samples of wastewater were obtained from same printing facility. Aqueous dye solution was prepared by dissolving appropriate amounts of Cyan dye with deionized water to the desired concentration. The final $\mathrm{pH}$ of the solution was adjusted by $0.10 \mathrm{molL}^{-1}$ $\mathrm{NaOH}$ and $\mathrm{H}_{2} \mathrm{SO}_{4}$. Deionized water was used throughout this experiment.

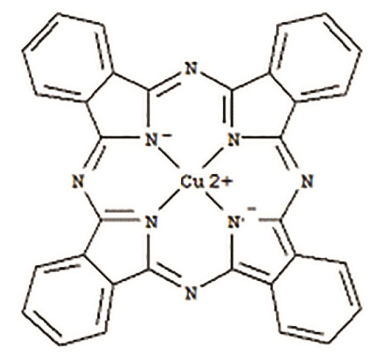

Figure 1: Chemical strucuture of Cyan pigment

\subsection{Preparation and characterization of $n Z \mathrm{VI}$}

nZVI particles were prepared through the "green" synthesis method, as previously reported by Machado et al (2013) where $37 \mathrm{~g}$ of dried oak leaves were mixed with $1000 \mathrm{ml}$ of deionized water on a magnetic stirrer for $20 \mathrm{~min}$ at $80^{\circ} \mathrm{C}$. The resulting mixture was filtered with Büchner Vacuum Filtration Funnel and $0.1 \mathrm{M} \mathrm{Fe}(\mathrm{III})$ solution was added in the mixture in a volume ratio of 1 : 3. Ferric iron was reduced to Fe(0) and ZVI particles precipitated instantly according to the mixture color turned from yellow to dark brown. In that way, a Fe(0) concentration of $1.395 \mathrm{gL}^{-1}$ in nanomaterial was obtained.

The structure, composition, particle shape and size distribution of the prepared nanomaterial were characterized by Scanning electron microscopy (SEM; Hithchi S-4700 Type II), energy dispersive spectrum (EDS) and transmission electron microscopy (TEM; Philips CM 10). 
The synthesized nanoparticles are characterized by a spherical shape and a size of about $50 \mathrm{~nm}$, without expressed particle aggregation and agglomeration (Figure 2), due to dispersive and stabilizing characteristics of oak leaves (Poguberović et al, 2016).

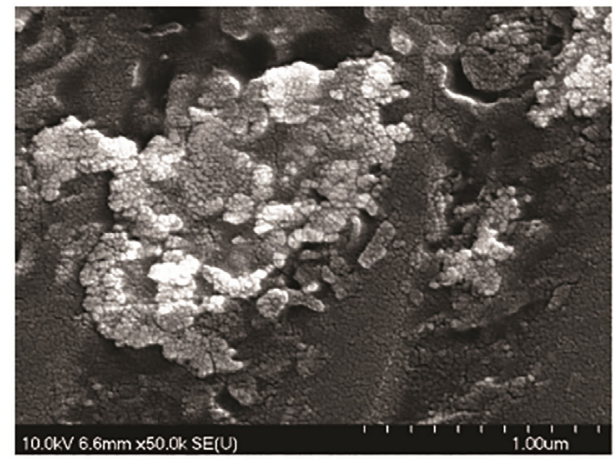

a)

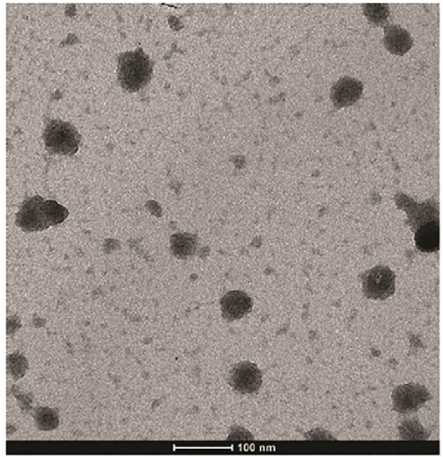

b)

Figure 2: a) SEM i b) TEM microscopic display of nano zero valent iron (Poguberović et al, 2016)

\subsection{Experimental procedure}

A different dose of $\mathrm{nZVI}\left(0.75-60 \mathrm{mgL}^{-1}\right)$ was added in a samples of $250 \mathrm{~mL}$ aqueous dye solution within a dye concentration of $20-180 \mathrm{mgL}^{-1}$. After the $\mathrm{pH}$ adjustment with $\mathrm{NaOH}$ and $\mathrm{ccH}_{2} \mathrm{SO}_{4}$ a certain amount of $\mathrm{H}_{2} \mathrm{O}_{2}$ (1-11 mM) was added in the mixture. Samples were shaken in a glass beaker on a JAR apparatus (FC6S Velp Scientific, Italy) at $120 \mathrm{rpm}$ and constant temperature of $23^{\circ} \mathrm{C}$.

After the reaction time has elapsed, residual Cyan concentration was determined in the filtrate by measuring the absorbance of the aqueous solutions at $636 \mathrm{~nm}$ with UV/VIS spectrophotometer (UV-1800 PG Instruments Ltd T80+ UV/VIS, Japan). The Cyan removal efficiency was calculated using the equation (1):

$E(\%)=A_{0}-A / A_{0} * 100$

where the $A_{0}$ indicates the absorption of dye before Fenton-like treatment and $A$ indicates the dye absorption after the treatment.All the experimental data were recorded in duplicate.

\subsection{Statistical analysis}

To quantify and elucidate the effects of four influencing factors (intial dye cocnentrations, catalyst dosage, $\mathrm{pH}$ and hydrogen peroxide concentrations) on Cyan removal efficiency, a new three-level design of experiments - DSD was selected to develop mathematical models. Besides the fact that allows a significant reduction in the number of experiments, DSD is very effective in estimating linear and nonlinear effects. In that way assessment of active effects, two-factor interactions effects, and purely quadratic effects in a single step with a minimal number of runs can be obtained. The specific levels for each factor are listed in Table 1. A total of 28 runs were designed: 13 experimental runs conducted in duplicate with two extra central points. By invoking the Effect Sparsity Principle, a model-selection strategy could determine which effects are actually active (Libbrecht et al, 2015).

Table 1: Factors and Levels for Cyan removal efficiency

\begin{tabular}{|l|c|c|c|c|c|}
\hline \multirow{2}{*}{ Factors } & Value & Coded value & \multicolumn{3}{|c|}{ Level } \\
\cline { 2 - 5 } & & & -1 & 0 & +1 \\
\hline Initial dye concentration & $\mathrm{mgL}^{-1}$ & $\mathrm{X} 1$ & 20 & 100 & 180 \\
\hline Catalyst dosage & $\mathrm{mgL}^{-1}$ & $\mathrm{X} 2$ & 0.75 & 30 & 60 \\
\hline $\mathrm{pH}$ & - & $\mathrm{X} 3$ & 2 & 6 & 10 \\
\hline Hydrogen peroxide concentration & $\mathrm{mM}$ & $\mathrm{X} 4$ & 1 & 6 & 11 \\
\hline
\end{tabular}




\section{RESULTS AND DISCUSSIONS}

\subsection{Evaluation of DSD model}

In order to characterize the system under the influence of different process conditions: dye concentration, catalyst dosage, $\mathrm{pH}$ and hydrogen peroxide concentration, DSD statistical analysis was applied. The results of the 28 experimental runs indicated decolorization efficiency range from 1.67 to $83.45 \%$ for Fenton-like process. In this way, the assumption that the Cyan removal process is largely dependable on the applied experimental conditions is confirmed, and it may be concluded that the individual parameters contribute to the efficiency of the Fenton process to a certain extent.

In order to derive the regression model that best fits the obtained results, JMP's regression analysis was applied. The regression model includes the first-order (main effects), second-order (quadratic), and twoway interaction terms and they were fit using a forward stepwise regression. Three popular modern measures of model performance: the corrected Akaike Information Criterion (AICC) and the Bayesian Information Criterion (BIC) and RMSE (Root Mean Square Error) were used to determine a model that best predicted process performance. Smaller values of AICC and BIC indicate better prediction capability or performance. In addition to the standard selection criteria, the models should contain all tested input parameters, which is from the engineering point of view extremely important in this problem.

Analysis of variance (ANOVA) was performed to provide more information concerning the model and the results are presented in Table 2 . The quadratic regression model is statistically significant as $p$-value is less than 0.05 , suggesting 95\% confidence level. Moreover, due to the p-value higher than 0.05, lack of fit test is not significant, which is desirable, as it indicates that any predictor left out of model is considered unsignificant and the established model predicts the experimental data very well.

Table 2: ANOVA results

\begin{tabular}{|c|c|c|c|c|}
\hline Source & DF & SS & MS & F ratio \\
\hline Model & 11 & 19914.545 & 1810.41 & 41.414 \\
\hline Error & 16 & 699.446 & 43.72 & Prob $>$ F \\
\hline C. Total & 27 & 20613.991 & - & $<0.0001$ \\
\hline Lack of Fit & 14 & 691.127 & 49.366 & 1.550 \\
\hline Pure error & 2 & 8.319 & 4.159 & Prob $>F$ \\
\hline Total error & 16 & 699.446 & - & 0.0803 \\
\hline
\end{tabular}

The $R^{2}$ value of $97 \%$ demonstrates that the quadratic regression model fits the data properly. The value of adjusted $R^{2}$ is $94.3 \%$, which reveals good relationship between the expected values and the actual values. A very small difference between these two coefficients indicates the absence of too much overfitting.

Table 3: The chosen regression model

\begin{tabular}{|l|c|}
\hline Descriptive factor & Value \\
\hline$R^{2}$ & 0.966 \\
\hline$R^{2}$ Adjusted & 0.943 \\
\hline$R M S E$ & 6.612 \\
\hline Mean of response & 30.436 \\
\hline Number of experiments & 28 \\
\hline
\end{tabular}

The coefficients of significant main parameters, their square members and dual factor interactions for the obtaiend model obtained are shown in Table 4. 
Table 4: Significant main parameters coefficients, their square members and dual factor interactions for the obtained model

\begin{tabular}{|l|c|c|c|c|}
\hline Factor & $\begin{array}{c}\text { Estimated } \\
\text { parameters }\end{array}$ & Standard error & $t$ value & Probability> $|t|$ \\
\hline Dye concentration & -2.918 & 1.478 & -1.97 & 0.0659 \\
\hline Catalyst dosage & -1.067 & 1.478 & -0.72 & 0.4811 \\
\hline $\mathrm{H}_{2} \mathrm{O}_{2}$ concentration & -1.043 & 1.478 & -0.71 & 0.4909 \\
\hline $\mathrm{pH}$ & -26.380 & 1.478 & -17.84 & $<0.001$ \\
\hline $\mathrm{Fe} * \mathrm{Fe}$ & -3.881 & 3.281 & -1.18 & 0.2542 \\
\hline $\mathrm{Dye}{ }^{*} \mathrm{H}_{2} \mathrm{O}_{2}$ & -7.707 & 2.014 & -3.83 & 0.0015 \\
\hline $\mathrm{Fe} * \mathrm{H}_{2} \mathrm{O}_{2}$ & -1.075 & 1.867 & -0.58 & 0.5729 \\
\hline $\mathrm{H}_{2} \mathrm{O}_{2} * \mathrm{H}_{2} \mathrm{O}_{2}$ & -19.293 & 3.086 & -6.25 & $<0.001$ \\
\hline $\mathrm{pH}^{*} \mathrm{pH}$ & 36.006 & 3.518 & 10.23 & $<0.001$ \\
\hline
\end{tabular}

Bold values indicate statistically significant model factors, specifically the $\mathrm{pH}$ value, interaction between dye and hydrogen peroxide concentration, as well as the square member of $\mathrm{pH}$. The order of significance is determined based on the estimated values of the parameters: $\mathrm{pH}<\mathrm{H}_{2} \mathrm{O}_{2} * \mathrm{H}_{2} \mathrm{O}_{2}<$ dye $* \mathrm{H}_{2} \mathrm{O}_{2}<\mathrm{pH}^{*} \mathrm{pH}$.

\subsection{Optimization of nZVI-induced Fenton process}

Despite the limited number of papers that implement DSD analysis as the main factor of the experiment, it has been established that the capability and flexibility of the JMP 13 software can provide significant advancement in the optimization process, which, for the ultimate goal, maximizes the dye removal efficiency compared to the technological conditions described in Table 1. The optimization of the process conditions is carried out within the limits of the tested variables (Table 1). The prediction profile with optimal values is shown in Figure 3.

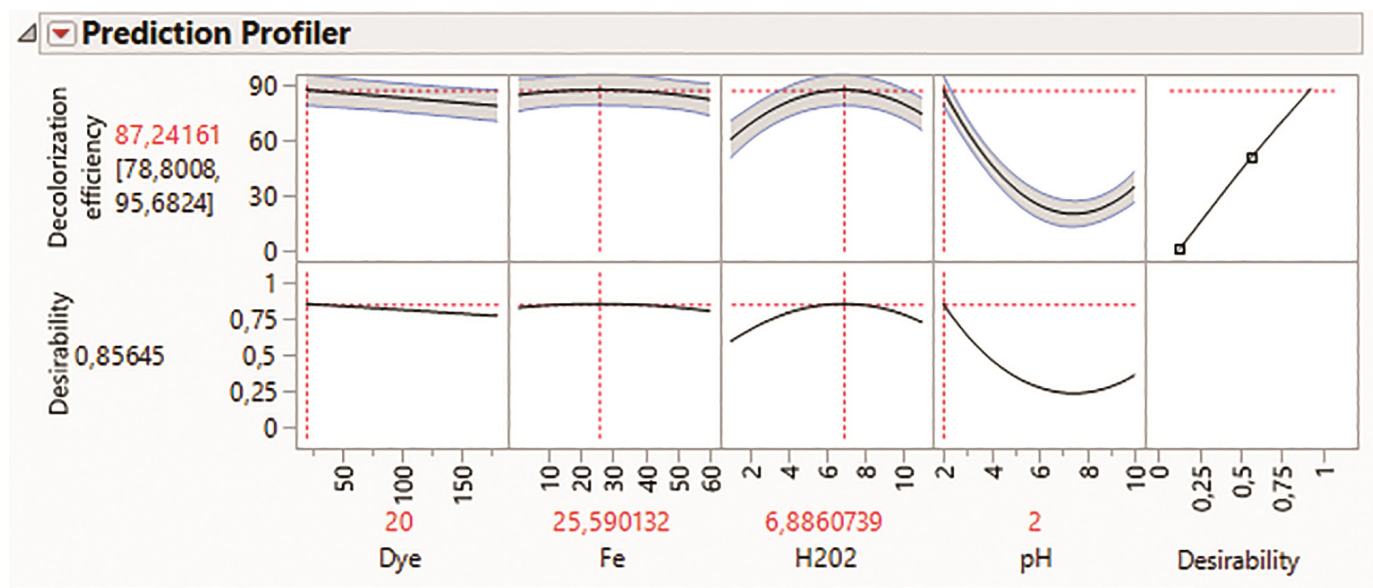

Figure 3: Optimal process conditions for nZVI-induced Fenton process

Based on the obtained results, the following optimal conditions were determined: dye concentration of $20 \mathrm{mgL}^{-1}$, catalys dosage of $25.59 \mathrm{mgL}^{-1}, \mathrm{pH}$ value of 2 and hydrogen peroxide concentration of $6.89 \mathrm{mM}$, where the statistical model proposes the process efficiency of $87.24 \%$. The obtained results are consistent with the significant factors shown in Table 4, indicating that the decolorization efficiency increases significantly with the decrease of $\mathrm{pH}$ and dye concentration. The experimental verification of the process optimization was performed with eight additional experiments, yielding the following decolorization efficiencies: 89.63; 84.78; 85.20; 83.50; 84.35; 83.58; 84.27; 90.73. On the basis of experimentally obtained values, a $95 \%$ confidence interval was calculated [83.41-88.09\%]. The value of decolorization efficiency predicted by the adopted regression model (Figure 3 ) is $87.24 \%$ and fits in the experimentally obtained confidence interval, which shows that the adopted regression model good describes the process of dye removal. 


\subsection{Real effluent treatment}

In order to determine the possibility of using the synthesized nanomaterial, a real effluent generated after the printing process and colored with a cyan dye was subjected to nZVI-induced Fenton treatment within the optimal doses of the tested parameters. The dye removal efficiency was monitored for a period of 120 minutes and the results indicated that degradation efficiency after 60 minutes was $70.85 \%$ where the maximum efficacy was achieved with a longer reaction time, but with a slight increase (up to 76.69\%). Compared to the treated synthetic cyan dye solution, the efficiency of the Fenton process in the case of a real effluent was lower. This behavior is due to the presence of a various organic and inorganic compound in the complex effluent matrix. Different species can achieve an inhibitory effect on the dye degradation process, behaving as hydroxyl radical catchers and thereby achieving competition for active sites on the surface of the catalyst.

\section{CONCLUSIONS}

The results obtained in this work indicated that the DSD approach can be effectively used to investigate factors that affect decolorization efficiency during the nZVI-induced Fenton process. Four investigated process parameters (initial dye concentration, catalyst dosage, $\mathrm{pH}$ and hydrogen peroxide concentration) were studied via modeling using the DSD approach. Application of this experiment design method enabled a reduction of the large number of traditional experiments to only 28, where all experimental runs were performed in duplicate, followed with two additional central points. The accuracy and reliability of the mathematical models were confirmed by validation experiments.

Based on the experimental results, it can be concluded that the decolorization efficiency increases with the decrease of $\mathrm{pH}$ value and dye concentration, which are the most significant parameters. High decolorization efficiency, up to $87 \%$ is obtained in the case of synthetic dye solution, while a lower expected efficiency of $76 \%$ is achived within the wastewater treatment under determined optimal conditions.

This study enriches understanding of Fenton-like process for the cyan dye removal from synthetic dyes solution and real printing effluent and demonstrates that DSD is a feasible method to investigate the mechanism of Fenton-like process.

\section{ACKNOWLEDGMENTS}

The authors acknowledge the financial support of the Ministry of Education, Science and Technological Development of the Republic of Serbia within the Projects No. TR 34014 and III43005.

\section{REFERENCES}

[1] Bilińska, L., Gmurek, M., Ledakowicz, S.: “Comparison between industrial and simulated textile wastewater treatment by AOPs - Biodegradability, toxicity and cost assessment", Chemical Engineering Journal 306, 550-559, 2016. doi:https://doi.org/10.1016/j.cej.2016.07.100.

[2] Brito, M., Veloso, C., Santos, L., Bonomo, R., Fontan, R.: “Adsorption of the textile dye Dianix ${ }^{\circledR}$ royal blue $\mathrm{CC}$ onto carbons obtained from yellow mombin fruit stones and activated with $\mathrm{KOH}$ and $\mathrm{H}_{3} \mathrm{PO}_{4}$ : kinetics, adsorption equilibrium and thermodynamic studies", Powder Technology 339, 334 343,2018. doi: 10.1016/j.powtec.2018.08.017.

[3] Kecić, V., Kerkez, Đ., Prica, M., Lužanin, O., Bečelić-Tomin, M., Tomašević Pilipović, D., Dalmacija, B.: "Optimization of azo printing dye removal with oak leaves-nZVI/ $\mathrm{H}_{2} \mathrm{O}_{2}$ system using statistically designed experiment", Journal of Cleaner Production, 202, 65-80, 2018. doi:doi.org/10.1016/j.jclepro.2018.08.117.

[4] Kecić, V., Kerkez, Đ., Prica, M., Rapajić, S., Leovac Maćerak, A., Bečelić-Tomin, M., Tomašević Pilipović, D.: "Optimization of Cyan flexo dye removal by nano zero-valent iron using response surface methodology", Journal of Graphic Engineering and Design 8, 35 - 45, 2017. doi: 10.24867/JGED-2017-2-035.

[5] Khemila, B., Merzok, B., Chouder, A., Zidelkhir, R., Leclerc, J., Lapicque F.: "Removal of a textile dye using photovoltaic electrocoagulation", Sustainable Chemistry and Pharmacy 7, 27-35, 2018. doi: 10.1016/j.scp.2017.11.004. 
[6] Libbrecht, W., Deruyck, F., Poelman, H., Verberckmoes, A., Thybaut, J., De Clercq J., Van Der Voort, P.: "Optimization of soft templated mesoporous carbon synthesis using Definitive Screening Design", Chemical Engineering Journal, 259, 126-134, 2015. doi: 10.1016/j.cej.2014.07.113.

[7] Lin, C., Chiang, C., Nguyen, M., Lay, C.: "Enhancement of fermentative biohydrogen production from textile desizing wastewater via coagulation-pretreatment", International Journal of Hydrogen Energy 42 (17), 12153-2158, 2017. doi: 10.1016/j.ijhydene.2017.03.184.

[8] Lin, J., Ye, W., Baltaru, M., Tang, Y., Bruggen, B.: "Tight ultrafiltration membranes for enhanced separation of dyes and Na2SO4 during textile wastewater treatment", Journal of Membrane Science 154, 21-228, 2016. doi: 10.1016/j.memsci.2016.04.057.

[9] Machado, S., Pinto, S., Grosso, J., Nouws, H., Albergaria, J., Delerue-Matos, C.: "Green production of zero-valent iron nanoparticles using tree leaf extracts", Science of the Total Environment, 445-446, 1-8, 2013. doi: 10.1016/j.scitotenv.2012.12.033.

[10] Mijin, D.: "Printing dyes and adhezives", (Faculty of Technology and Metallurgy, Beograd, 2015). (in Serbian)

[11] Poguberović, S., Krčmar, D., Maletić, S., Konya, Z., Tomašević Pilipović, D., Kerkez, Đ., Rončevič, S.: "Removal of As(III) and $\mathrm{Cr}(\mathrm{VI})$ from aqueous solutions using "green"zero-valent iron nanoparticles produced by oak, mulberry and cherry leaf extracts", Ecological Engineering, 90, 42-49, 2016. doi: 10.1016/j.ecoleng.2016.01.083.

[12] Punzi, M., Anbalagan, A., Börner, R., Svensson, B.M., Jonstrup, M., Mattiasson, B.: "Degradation of a textile azo dye using biological treatment followed by photo-Fenton oxidation: Evaluation of toxicity and microbial community structure", Chemical Engineering Journal, 270, 290-299, 2015. doi:10.1016/j.cej.2015.02.042.

[13] Stefaniuk, M., Oleszczuk, P., Ok, Y.: "Review on nano zerovalent iron (nZVI): From synthesis to environmental applications", Chemical Engineering Journal 27, 618-632, 2016. doi: 10.1016/j.cej.2015.11.046.

[14] Wang, R., Xin, J., Wang, Z., Gu, W., Wei, Z., Huang, Y., Qiu, Z., Jin, P.: "A multilevel reuse system with source separation process for printing and dyeing wastewater treatment: A case study", Bioresource Technology 247, 1233-1241, 2018. doi: 10.1016/j.biortech.2017.09.150.

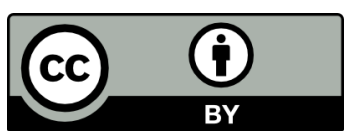

(C) 2018 Authors. Published by the University of Novi Sad, Faculty of Technical Sciences, Department of Graphic Engineering and Design. This article is an open access article distributed under the terms and conditions of the Creative Commons Attribution license 3.0 Serbia (http://creativecommons.org/licenses/by/3.0/rs/). 